REVISTA X, Curitiba, volume 14, n.5,p.291-303, 2019

\title{
PROJETO DE LETRAMENTO: APRENDIZAGEM DE LÍNGUAS COM RELATOS PESSOAIS DE GUERRA
}

Literacy Project: Language Learning with Personal War Reports

Itamara PETERS (SME - Curitiba; SEED - PR) ${ }^{1}$

\begin{abstract}
RESUMO: O presente texto traz os resultados de um projeto de letramento desenvolvido com estudantes do sétimo ano na Escola Municipal em Curitiba, 2018. O objetivo do trabalho estava em possibilitar que os estudantes interagissem com os conhecimentos sobre o tema que escolheram para as aulas de língua portuguesa e língua inglesa. A proposta do projeto foi desenvolvida dentro das atividades de um curso da extensão da Universidade Federal do Paraná em parceria com a Universidade de Otterbein, em que trabalhamos com uma professora cursista de Ohio acompanhando o planejamento e sugerindo propostas de atividades a serem desenvolvidas com os estudantes. A metodologia de trabalho utilizada para esta proposta foi a pesquisa ação, que visa compreender como a prática docente se configura e se organiza por meio de projetos de ensino e que efeitos de aprendizagem os projetos desencadeiam nos estudantes e professores. As atividades desenvolvidas durante o projeto comprovaram o envolvimento dos estudantes e o modo como os processos de letramento possam ser pensados a partir da integração de conteúdos nas aulas língua portuguesa e língua inglesa para que haja o reconhecimento, a valorização e o desenvolvimento das habilidades de leitura e escrita em diferentes línguas.
\end{abstract}

PALAVRAS-CHAVE: projeto de letramento; formação de professores; aprendizagem compartilhada.

\begin{abstract}
The text shows results of a literacy project developed with seventh grade school students from a Municipal School in Curitiba in 2018. The aim of the work was to enable students to interact with knowledge on the subject they chose for Portuguese and English language classes. The project proposal was developed within the activities of a course at the Federal University of Paraná in partnership with the University of Otterbein, in which we work with a trainee professor from Ohio accompanying the planning and suggesting proposals for activities to be developed with students. The methodology used for this proposal was the action research, which aims to understand how the teaching practice is configured and organized by means of teaching projects and what learning effects the projects trigger in students and teachers in the classroom. The activities developed during the project proved the involvement of students and the way in which literacy processes can be thought from the integration of content in the Portuguese language and English language classes for recognition, appreciation and development of reading and writing skills in different languages.
\end{abstract}

\footnotetext{
${ }^{1}$ Professora de Língua Portuguesa no programa SAREH/SEED-PR no Hospital Pequeno Príncipe, em Curitiba. Professora de Língua Inglesa na Rede Municipal de Educação de Curitiba (SME). Mestre em Letras pela Universidade Estadual do Norte do Paraná (UENP). itamarapeters@ gmail.com
} 
REVISTA X, Curitiba, volume 14, n.5,p. 291-303, 2019

KEYWORDS: literacy project; continuing teacher education; shared learning.

\section{PONTO DE PARTIDA}

Os estudos iniciais desta proposta de pesquisa e de desenvolvimento das ações deste projeto, aqui descrito,foram centrados nos conceitos de: letramentos, multiletramentos e co-teaching (co-ensino). Este projeto integrou uma proposta maior que foi delineada para formação continuada de professores de inglês em atividades de extensão na Universidade Federal do Paraná (UFPR).

O objetivo dessa proposta deformação continuada de professores era trabalhar com um grupo de professores de inglês, entre eles uma professora estrangeira que viria ao Brasil, no desenvolvimento e na vivência de projetos de letramento em língua inglesa em escolas municipais e estaduais públicas na cidade de Curitiba e região metropolitana. Esse intercâmbio de experiências docentes entre professores de Curitiba e professores de Ohio, EUA, fazia parte dos objetivos da formação continuada ofertada pela UFPR. Partindo dessas premissas e dos conceitos teóricos iniciais, a proposta do projeto que é compartilhada com os leitores neste relato foi delineada. Para a experiência que aqui está relatada, um grupo de estudantes da fase II do Ensino Fundamental foi convidado a participar; grupo este que era acompanhado por essa professora e pesquisadora no momento do estudo e que aqui relata a experiência vivenciada.

A intenção dos projetos de letramento foi a de desenvolver uma prática de sala de aula que fosse capaz de conjugar as necessidades de aprendizagem dos estudantes com o desenvolvimento de habilidades e conhecimentos em língua estrangeira. Desse modo, o projeto visava mobilizar, avaliar e ampliara capacidade de interação dos estudantes com a língua inglesa e o engajamento de professores e alunos na proposta de estudo desenvolvida. Como a professora, neste caso, era responsável tanto pelas aulas de português quanto das de inglês, houve uma aproximação interdisciplinar dos conteúdos das duas disciplinas, integrando assim aulas de português e inglês no projeto.

Desse modo, a proposta de estudo por projeto de letramento foi realizada com turmas de sétimo ano do Ensino Fundamental II, nas aulas de língua portuguesa e em algumas aulas de língua inglesa, na Escola Municipal Júlia Amaral Di’Lenna. A escola localiza-se na Barreirinha, saída de Curitiba para Almirante Tamandaré, e recebe, 
portanto, estudantes tanto do entorno da escola como do município vizinho. A temática adotada para construção das atividades surgiu do próprio interesse dos alunos com relação a guerras, especificamente em virtude do debate ocorrido em sala de aula por meio de imagens e reportagens veiculadas sobre a guerra na Síria. Tomamos este interesse de descoberta, de questionamento e de inquietação como elemento de motivação para o estudo e o debate dos efeitos da guerra. Assim, utilizamos a temática como ponto de partida do planejamento do projeto e construção dos materiais que foram realizados pelos alunos.

O trabalho foi realizado com três turmas, no total de 98 estudantes, que constituíam grupos muito heterogêneos de trabalho. Os grupos eram compostos de estudantes com excelente nível acadêmico que apresentavam um repertório de linguagem muito bem desenvolvido e estudantes com sérias dificuldades de domínio do código escrito e das habilidades de leitura e escrita. Além disso, duas das três turmas tinham estudantes ditos "inclusos", mas que não se integravam muito bem à rotina da sala de aula e ao processo de aprendizagem, necessitando intervenção neste aspecto também.

Diante deste cenário, este texto caracteriza-se como um relato de experiência e tem por objetivo compartilhar com os leitores experiências vivenciadas pelo grupo de professores em formação continuada e o trabalho desenvolvido com os alunos, como já mencionado. Com o intuito de auxiliar a compreensão dos leitores, este relato está organizado a partir deste texto contemplando aporte teórico, descrição da aplicação da proposta na escola, resultados observados e discussões finais.

\section{APORTE TEÓRICO}

No Brasil, os estudos sobre letramentos envolvem discussões e preocupações que trazem o conceito de letramento para além dos muros da escola. Kleiman, por exemplo, aponta que "Letramento é um conceito criado para referir-se aos usos da língua escrita não somente na escola, mas em todo lugar, porque a escrita está por todos os lados [...]" (KLEIMAN, 2005, p. 05), ou seja, o letramento refere-se as práticas sociais da leitura e da escrita, extrapolando o mero domínio do código linguístico.

Dessa maneira, o conceito de letramento procura explicar o impacto e a necessidade das práticas letradas em toda a sociedade, não apenas no âmbito e espaço 
escolar, mas principalmente quando entende a necessidade de tratar a linguagem como uma prática social. De acordo com Soares (1999), o termo letramento tem sua "origem etimológica em Literacy que vem do Latin, littera (letra), com o sufixo - cy, que denota qualidade, condição, estado, fato de ser. Litterate é, portanto, aquele indivíduo que tem a condição de ler e escrever de forma legitimada socialmente" (SOARES, 1999, p. 17). O conceito de letramento compreende a ideia de que a escrita enquanto construto social está imbuída em si das “consequências sociais, culturais, políticas e econômicas”, tanto para o grupo como para os indivíduos inseridos em ambientes letrados.

Outros autores como Street (2014) e Barton \& Hamilton (2003) definem letramento numa relação direta com o uso social da linguagem vinculado às práticas linguísticas e à cultura do grupo ao qual tais aspectos vão sendo pensados e delineados. Street afirma que:

[o] conceito de práticas de letramento se coloca num nível mais alto de abstração e se refere igualmente ao comportamento e às conceitualizações sociais e culturais que conferem sentido aos usos da leitura e/ou da escrita. As práticas de letramento incorporam não só os 'eventos de letramento', como ocasiões empíricas às quais o letramento é essencial, mas também modelos populares desses eventos e as pré-concepções ideológicas que os sustentam (STREET, 2014, p. 18).

Assim, o conceito de letramento significa, entre outras coisas, compreender o sentido numa determinada situação como sendo fruto de um produto cultural; por isso, uma prática de letramento escolar poderia implicar um conjunto de atividades visando ao desenvolvimento de estratégias ativas de compreensão da língua, ampliação lexical e das informações para aumentar o conhecimento do aluno e à sua fluência, ampliando níveis de proficiência.

Klein aponta que "[o] letramento adquire múltiplas funções e significados, dependendo do contexto em que ele é desenvolvido, isto é, da agência de letramento por ele responsável" (KLEIMAN, 1998, p. 182). Logo pressupõe-se que a escola seja um espaço de letramento, mas é necessário que se perceba nela as necessidades de desenvolvimento de práticas letradas e quais práticas sociais de linguagem emergem deste contexto. Entende-se assim que "os letramentos escolares devem ser vistos como práticas sociais críticas, pois devem considerar todos os aspectos que envolvem os eventos de letramento desenvolvidos no espaço educativo" (PETERS, 2016, p. 33). 
Nesta perspectiva, Street (2014) ressalta que há múltiplos elementos que devem ser considerados no processo de escolarização,

\begin{abstract}
uma reconfiguração do letramento como prática social crítica exige que levemos em conta essas perspectivas históricas e também transculturais na prática de sala de aula e que auxiliemos alunos a situar suas práticas de letramento (STREET, 2014, p. 149).
\end{abstract}

Dessa forma, pensar em práticas situadas em espaço escolar nos remete ao contexto de produção e desenvolvimento das práticas letradas, pois elas são determinantes em todas as etapas de desenvolvimento de processos de letramento. Compreende-se que a escolarização é, do ponto de vista coletivo, o mecanismo mais eficaz de promoção de inclusão social. No entanto, este ponto de vista só se concretiza se a escola considerar de fato o seu papel diante dos eventos e práticas sociais de letramento. Considerando que as práticas letradas colocam, de acordo com Mollica (2014), "os falantes com maiores chances de construir cidadania plena", os processos de letramento corroboram no desenvolvimento de sujeitos mais críticos, conscientes e criativos.

Ainda segundo Mollica, através da escola, acredita-se que "o indivíduo se torne agente ativo e transformador" (MOLLICA, 2014, p. 13). É a partir da inserção em ambientes letrados e multiletrados que o desenvolvimento das habilidades linguísticas vai ocorrendo e sendo ampliado na medida em que se constituem como instrumento de produção e interação com o conhecimento. $\mathrm{O}$ sentido de multiletramento adotado aqui está de acordo com Rojo (2012), ou seja, trata-se de um conceito que engloba as atuais discussões referentes aos "novos estudos do letramento", dando ênfase não só à multiplicidade e variedade das práticas letradas da nossa sociedade, mas também fazendo referência à multiplicidade cultural e semiótica de constituição dos textos, bem como a uma gama de suportes e meios de circulação dos textos e dos processos comunicativos.

A questão que se coloca, entretanto, é como esses processos de letramento poderiam de fato serem pensados no âmbito escolar. Diante de tal pergunta, alguns caminhos são apresentados a partir de desenvolvimento de projetos, como os projetos de letramento que trazem o conceito de uma "escola aberta" ou plural. O trabalho com projetos, segundo Oliveira, Tinoco e Santos (2014), pauta-se na relação direta com as práticas sociais de linguagem e na função dual da escola: conhecimento científico e 
conhecimento para a vida, focando no desenvolvimento humano e na construção de conceitos de cidadania, emancipação social e empoderamento.

Por essa razão, compreendemos que o ensino por projetos permite que os conteúdos curriculares sejam trabalhados de maneira integrada, sistêmica, proporcionando como resultado uma educação interdisciplinar e uma visão de mundo integrada. Para os autores, "aprender por projetos é aprender respondendo a uma necessidade vinculada a uma prática social" (OLIVEIRA; TINOCO; SANTOS, 2014, p. 48), ou seja, um projeto de letramento visa a aprendizagem integrada e integral e pode ser definido como uma

prática social em que a escrita é utilizada para atingir algum outro fim, que vai além da mera aprendizagem da escrita (a aprendizagem dos aspectos formais apenas), transformando objetivos circulares como 'escrever para aprender a escrever' e 'ler para aprender a ler' em ler e escrever para compreender e aprender aquilo que for relevante para o desenvolvimento e realização do projeto" (KLEIMAN, 2000, p. 238 apud OLIVEIRA; TINOCO; SANTOS, 2014, p. 47).

Pode-se depreender dos apontamentos das autoras que o trabalho com projetos nas aulas de línguas tem o potencial de trazer a prática social da linguagem para a aula e alterar o foco do processo de aprendizagem linguística, indicando a finalidade do ato de escrever e ler. Ou seja, a utilização da língua faz-se necessária para responder as necessidades que emergem do processo de aprendizagem, logo utiliza-se a leitura, a escrita, a oralidade para realizar o projeto e responder as demandas impostas por ele. Oliveira, Tinoco e Santos afirmam ainda que o projeto de letramento trabalha com "ações de leitura e escrita" que "viabilizam a análise de um problema social para o qual se buscam a compreensão e as alternativas de solução" (OLIVEIRA; TINOCO; SANTOS, 2014, p. 48). Desse modo, o projeto é compreendido como um instrumento de intervenção e ação diante de uma realidade posta. Ainda pensando nas formas de atuação por meio da linguagem e na compreensão dos conceitos de projetos e nos processos de letramento, Rojo aponta que:

uma educação linguística adequada a um alunado multicultural se configura, [...] como aquela que possa trazer aos alunos projetos (designs) de futuro que considerem três dimensões: a diversidade produtiva (âmbito do trabalho), o pluralismo cívico (no âmbito da cidadania) e as identidades multifacetadas (no âmbito da vida pessoal) (ROJO, 2013, p. 14). 
Dessa forma, entendemos que o trabalho com projetos no ensino de línguas funda-se na concepção de currículo aberto, que estabelece uma relação direta entre vida e escola, na construção de um conhecimento que caminha para a emancipação dos sujeitos. Assim, um projeto de letramento parte de uma necessidade comunicativa real, buscando mecanismos de compreensão e interação com a linguagem que emerge da prática social dos sujeitos envolvidos.

Em busca de uma educação linguística adequada às experiências vivenciadas em projetos de letramento, práticas de co-teaching ou co-ensino tem se mostrado um mecanismo eficiente nos processos de ensino. Inicialmente chamada de "educação especial", a técnica de co-ensino envolve dois ou mais profissionais que atuam com um mesmo grupo, simultaneamente, visando objetivos comuns. De acordo com Cushman (2004), “os profissionais compartilham responsabilidades de ensinar um grupo de estudantes, sendo que tal processo envolve distribuição de responsabilidade, compartilhando planejamento, instrução e avaliação das atividades em sala de aula" (CUSHMAN, 2004, p. 05).

Ainda de acordo com Cushman ${ }^{2}$ (2004), a atividade de co-teaching é composta por alguns elementos, tais como: busca de pelo menos um objetivo comum; o compartilhar de crenças que promovem apoio mútuo, compreendendo que cada membro apresenta características necessárias ao trabalho do grupo; engajamento no processo simultâneo de ensinar e aprender; exercício de liderança e de coordenação compartilhada entre os membros da equipe; e ainda, pressupõe um processo cooperativo que se dá face a face (CUSHMAN, 2004, p. 05).

Em virtude dos princípios de co-teaching serem os de desenvolver colaborativamente habilidades dos docentes no intuito de planejar, executar e avaliar processos de ensino, em prol do desenvolvimento de um grupo de estudantes, é que a proposta foi experimentada durante o projeto de letramento, na escola municipal citada acima, envolvendo professores de diferentes redes de ensino e uma professora estadunidense.

\footnotetext{
${ }^{2}$ No original: "1. Coordinate their work to achieve at least one common, publicly agreed-on goal; 2. Share a belief system that supports the idea that each of the co-teaching team members has unique and needed expertise; 3 . Demonstrate parity by alternatively engaging in the dual roles of teacher and learner, expert and novice, giver and recipient of knowledge or skills; 4. Use a distributed functions theory of leadership in which the task and relationship functions of the traditional lone teacher are distributed among all co-teaching team members; 5 . Use a cooperative process that includes face-to-face interaction, positive interdependence, interpersonal skills, monitoring co-teacher progress, and individual accountability".
} 


\section{PROJETO DE LETRAMENTO EM UMA ESCOLA MUNICIPAL: AS ATIVIDADES VIVENCIADAS}

Conforme mencionado nas considerações iniciais, no curso de Formação Intercultural e Internacional de professores da Universidade Federal do Paraná, iniciamos as discussões para elaboração de um projeto de ensino-aprendizagem de línguas em uma formação compartilhada entre a UFPR e a Universidade de Otterbein, ou seja, o trabalho seria desenvolvido em parceria entre professores brasileiros e professores estadunidenses. Para isso, foram criados grupos de trabalho compostos por professores brasileiros e, pelo menos, um professor de Otterbein e, a partir da organização dos grupos foram iniciadas as atividades de planejamento e elaboração dos materiais didáticos que seriam utilizados durante as aulas.

As discussões iniciais envolveram a conceituação da proposta de letramento e a elaboração de um projeto de letramento que seria vivenciado nas turmas de atuação docente dos professores brasileiros. Porém, o grupo que iria atuar com os estudantes do sétimo ano tomou como base, para elaboração do projeto, o interesse manifestado pelos estudantes de aprendizagem sobre as guerras, como já mencionado anteriormente.

Ao retomar a conversa sobre o noticiário da televisão, os estudantes mencionaram a guerra na Síria como um fato que atraiu a atenção e despertou a curiosidade sobre o assunto. A proposta de estudo foi elaborada a partir desse tema relacionado a outros textos do gênero narrativo que estavam em análise para também compor o rol de materiais do segundo trimestre letivo.

Iniciamos os estudos e discussões a partir de um texto do livro didático adotado pela escola, com o gênero história pessoal, o qual citava o livro Diário de Anne Frank como pano de fundo da história. Foi a partir dessas ideias e conversas iniciais que os estudantes selecionaram o assunto guerra, que seria então estudado e discutido nas aulas seguintes. Após a seleção do assunto, os alunos pesquisaram filmes e livros que tratavam de experiências no contexto de guerras. O objetivo principal foi o de conhecer os horrores do holocausto e de outras guerras para desenvolver a consciência do sofrimento de seus semelhantes. Vinculados ao objetivo central, outros objetivos que envolviam tanto questões atitudinais como o domínio do código linguístico, da leitura e da escrita foram estabelecidos. 
Inicialmente, o projeto seria desenvolvido totalmente em língua inglesa, mas a escolha dos livros por parte dos estudantes e a disciplina ministrada pela docente (língua portuguesa) a este grupo de estudantes especialmente, exigiram a seleção de atividades que conjugavam língua portuguesa e língua inglesa, o que deixou o projeto mais interdisciplinar. Assim, o projeto foi desenvolvido em etapas e foi muito além do que estava planejado inicialmente, pois os estudantes contribuíram ricamente, pesquisando sobre o assunto a trazendo para as aulas as suas descobertas. Trabalhamos inicialmente a leitura dos textos literários estabelecendo um paralelo entre livro e filme de " $O$ diário de Anne Frank". Realizamos ainda a visita ao Museu do Expedicionário ${ }^{3}$, na cidade de Curitiba, e lá fizemos uma coleta de material linguístico que foi fotografado pelos alunos. Retomando o estudo, trabalhamos com a leitura e identificação do material em sala de aula, observando o gênero utilizado e a finalidade do material linguístico utilizado em imagens, vídeos e textos diversos.

$\mathrm{Na}$ sequência, os estudantes selecionaram fotos da visita ao museu e criaram legendas para tais fotos.Em uma etapa seguinte,retomamos a questão da imagem realizando a leitura da capa do filme "Barefoot Gin",comparando-a com a imagem da capa do livro "A última mensagem de Hiroshima". Ainda, assistimos ao trailer do filme e estudamos o poema "A rosa de Hiroshima", buscando estabelecer uma relação intertextual entre o poema, sua temática e outros textos já vistos anteriormente. Fechamos as discussões com um trabalho musical, estudando em língua inglesa a música "Imagine" e em língua portuguesa "O senhor da guerra".

Após a etapa de leitura reflexiva e estudo dos materiais selecionados e ou coletados por meio de imagens no museu, propomos atividades que envolviam os sentimentos com relação ao sofrimento das pessoas nas guerras. Para isso, estudamos adjetivos elaborando um dicionário ilustrado de sentimentos. Esta etapa do projeto foi desenvolvida em colaboração com a professora de Ohio e outros professores brasileiros envolvidos no projeto. O dicionário foi produzido com vocábulos pesquisados e selecionados pelos estudantes e desenhos que cada um deles fez sobre os sentimentos que identificou com relação à guerra.

\footnotetext{
${ }^{3}$ O Museu do Expedicionário é um espaço temático que ilustra, de forma didática, a participação dos soldados do Brasil no último conflito mundial. O museu exibe de modo permanente material histórico, como fotografias, filmes, mapas, livros e ilustrações, referente à participação brasileira na II Guerra Mundial, através da Força Expedicionária Brasileira, da Força Aérea Brasileira e da Marinha de Guerra do Brasil. Há também peças e documentos cedidos pelas diversas nações envolvidas no conflito que podem ser observados por seus visitantes.
} 
Finalizamos as atividades do projeto com a produção de um relato pessoal, no qual os estudantes descreveram a experiência que tiveram com os estudos realizados durante o projeto, envolvendo todas as atividades mencionadas acima.

\section{RESULTADOS OBSERVÁVEIS}

O desenvolvimento de um projeto de ensino em parceria com outros colegas em uma prática de co-ensino foi capaz de nos mostrar que o envolvimento dos professores em processos de letramento exige compromisso, envolvimento coletivo e consideração das necessidades de aprendizagem por parte dos estudantes. Foi possível observar e compreender também que a proposta teve resultados positivos por ter o engajamento e o envolvimento total dos alunos, indicando como a sala de aula pode ter seus sentidos ressignificados.

Tendo em vista que co-ensino é uma proposta de ensino colaborativo,a qual envolve dois ou mais professores compartilhando a responsabilidade do ensino de um determinado conteúdo, percebemos na prática o efeito desse processo nos estudantes. As experiências e tentativas de comunicação em língua inglesa por parte dos estudantes apontam que houve entendimento da língua utilizada e que a parceria estabelecida entre os professores foi eficiente para construir sentidos em grupo.

Outro fator importante que pode ser considerado é o nível de inclusão dos estudantes nas propostas de ensino-aprendizagem, pois o projeto foi capaz de envolver todos, apontando possibilidades inclusive aos estudantes que necessitam de adaptações no processo de ensino, ou seja, promovendo uma inclusão real nas atividades escolares. Além disso, outro ponto importante que pode ser levantado está relacionado aos objetivos do ensino compartilhado. A proposta desenvolvida com o sétimo ano foi capaz de provar os benefícios de elementos de co-ensino citados anteriormente (ver nota de rodapé 2). Ainda, a experiência de apresentar e colocar os estudantes em contato com sujeitos de outros contextos, nacionalidades e repertórios foi riquíssima. Foi um momento único para todos os estudantes e proporcionou aprendizagem tanto da língua inglesa quando da língua materna.

A colaboração entre colegas docentes evidenciou um caminho inovador, mais seguro e assertivo para os professores, quebrando a lógica da responsabilidade individual e solitária do docente no processo de planejar, ensinar e avaliar a 
aprendizagem. Entende-se, portanto, que quando as parcerias são estabelecidas, os benefícios são coletivos e os resultados são mais concretos.

Ainda, retomando os estudos dos letramentos a partir do que discorre Rios (2004) compreendemos que nos eventos de letramento "os papéis dos participantes, suas identidades sociais e os sentidos dos textos são dinâmicos, [...] os sentidos dos materiais escritos e as identidades sociais são negociados e reestruturados pelos participantes no curso mesmo do evento" (RIOS, 2014, p. 178). Isso nos faz considerar a importância das trocas e parcerias estabelecidas entre os professores e estudantes no desenvolvimento de projetos de letramento e práticas de co-teaching.

Outras constatações do desenvolvimento da proposta na escola referem-se à capacidade que os projetos apresentam de tomar rumos distintos e ir além dos caminhos planejados ou fugir da sua intenção inicial. Desse modo, é necessário atenção dos docentes e pesquisadores para que o objetivo principal não seja perdido durante a execução e outras possibilidades em sala de aula possam ser vivenciadas. O projeto exige um envolvimento muito grande dos participantes, ou seja, não é fácil organizar um projeto de co-teaching nas classes e escolas brasileiras. O sistema educativo apresenta grandes entraves para a concretização das propostas uma vez que a organização escolar nem sempre contribui para que as propostas se efetivem com a estrutura de horários muito fechados e sem flexibilidade, o que pode dificultar a execução dos projetos.

Por fim, reconhecemos que o projeto de letramento é um espaço para reflexão e desenvolvimento real de leitura, oralidade, escrita e cidadania, pois permite a discussão de fatos e questões importantes para os estudantes, trazendo a prática social da linguagem e os aproximando das finalidades do processo de aprendizagem linguística.

\section{CONSIDERAÇÕES FINAIS}

O texto buscou relatar de modo sucinto a experiência vivida e as impressões da experiência de um projeto de letramento interdisciplinar em língua portuguesa e língua inglesa em uma escola municipal com estudantes de sétimo ano. As constatações do projeto indicam uma quebra de barreiras e a desmistificação em relação à língua inglesa e as capacidades comunicativas dos adolescentes. Todo o desenvolvimento da proposta de trabalho planejada envolveu atividades com a linguagem, exigindo leitura, escrita, 
compreensão e interação com os textos trabalhados. A resposta a cada uma das etapas do projeto, seja pela interação dos estudantes com a oralidade ou por meio da escrita, deixou claro que houve compreensão e entendimento da língua utilizada.

As interações com os conteúdos envolvidos no projeto e com os outros professores alteraram o padrão de percepção tanto dos estudantes com relação aos professores como dos professores com relação aos estudantes e o processo de aprendizagem de línguas, evidenciando as múltiplas possibilidades de trabalho que podem surgir a partir dos projetos de letramento. Outro ponto importante e marcante do projeto foi o desenvolvimento da capacidade de lidar com as diferenças e estabelecer a quebra de estereótipos na medida em que cada um conviveu com o outro que não era da sua cultura, que não falava a sua língua, etc. outros processos de relação foram se estabelecendo e alterando conceitos.

\section{REFERÊNCIAS}

CUSHMAN, S. What is co-teaching? Villa Guide to Co Teaching, Chapter 1, p. 01-09, 2004.

INDIANA UNIVERSITY. CO-TEACHING: Purpose and Definition. Disponível em: https://www.iidc.indiana.edu/pages/co-teaching. Acesso em: 01 mai., 2019.

KLEIMAN, A. Preciso ensinar o letramento? Não basta ensinar a ler e a escrever? CEFIEL/IEL/UNICAMP, Campinas, 2005.

KLEIMAN, A. Os Significados do Letramento: uma nova perspectiva sobre a prática social da escrita. Campinas: Mercado das Letras, 1995.

KLEIMAN, A. Ação e Mudança na Sala de Aula: Uma pesquisa sobre letramento e interação. In: ROJO, R. Alfabetização e Letramento: perspectivas linguísticas. São Paulo: Mercado das Letras, 1998.

MOLLICA, M. C. Fala, Letramento e Inclusão Social. 2ed. São Paulo: Contexto, 2014.

OlIVEIRA, M.; TINOCO, G.; SANTOS, I. Projetos de letramento e formação de professores de língua materna. Natal: EDUFRN, 2014.

ROJO, R. Pedagogia dos multiletramentos: diversidade cultural e de linguagem na escola. In: ROJO, R.; MOURA, E. Multiletramentos na escola. São Paulo: Parábola, 2012.

ROJO, R. Escol@ conectada: os multiletramentos e as TICs. São Paulo, Parábola. 2013. 
PRODANOV, C.; FREITAS, E. Metodologia do trabalho científico: métodos e técnicas da pesquisa e do trabalho acadêmico. 2.ed., Novo Hamburgo: Feevale, 2013.

RIOS, G. Letramentos do mundo da vida e letramentos de sistemas: revisitando os letramentos dominantes. Signótica, v. 25, n. 2, p. 327-348. 2014.

SOARES, M. Letramento: um tema em três gêneros. São Paulo: Autêntica, 1999.

STREET, B. Letramentos Sociais: abordagens críticas do letramento no desenvolvimento, na etnografia e na educação. Trad. Marcos Bagno. São Paulo: Parábola, 2014. 